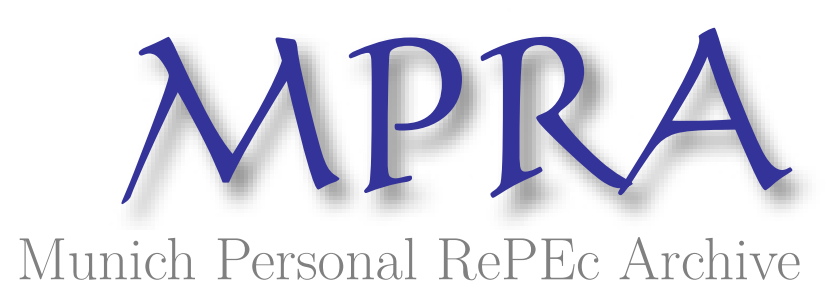

\title{
Tariff, Growth, and Welfare
}

Lee, Shun-Fa

Department of Industrial Economics

4 November 2010

Online at https://mpra.ub.uni-muenchen.de/27486/

MPRA Paper No. 27486, posted 20 Dec 2010 03:50 UTC 


\title{
Tariff, growth, and welfare
}

\author{
Shun-Fa Lee \\ Department of Industrial Economics, Tamkang University
}

November 2010

\begin{abstract}
We develop a two-country (Home and Foreign) by two-good (consumption good and investment good) by one factor (capital) endogenous growth model with international knowledge spillover to study the relationship between an import tariff and economic growth and welfare. First, unlike the past literature, we do not need to make an assumption such that the growth rates between countries are identical in a balanced growth path (BGP). Second, we show that there exists a unique and saddle-point BGP with both countries being incompletely specialized. Third, a higher import tariff on the consumption good in the domestic country may boost (reduce) the rate of economic growth when the foreign (domestic) country has an absolute advantage in the investment good. Finally, a rise in the tariff rate by one country may improve world welfare under some parameter spaces.
\end{abstract}

Keywords: two-country endogenous growth model, international knowledge spillover, import tariff, economic growth, welfare

JEL Classification: F13, F43, O41. 


\section{Introduction}

Innumerable articles and volumes have been published to extend the Ramsey-type endogenous growth model to various directions, such as Romer (1986) and Lucas (1988). However, only a few contributions extend these models to a two-country or multi-country economy to re-examine the trade issues and the long-run growth rate jointly in an unified framework. This paper attempts to provide such a framework. We develop a two-country (Home and Foreign) by two-good (consumption good and investment good) by one factor (capital) endogenous growth model with international knowledge spillover to study the relationship between an import tariff and economic growth and welfare.

There are four main results in this model. First, unlike the past literature, we do not need to make an assumption such that the growth rates between countries are identical in the balanced growth path (BGP). ${ }^{1}$ The main mechanism behind this is the international knowledge spillover that furthers the productivity in each country and correlates the long-run growth rates between countries. This mechanism is followed by the ideas of learning by doing and knowledge spillover in Arrow (1962) and Romer (1986) as well as the idea of intersectoral knowledge spillover in Drugeon and Venditti (2001), Nishimura and Venditti (2002), Drugeon et al. (2003), and Naito (2006b). Following these studies in the literature, the international knowledge available to the firms may be represented by the other country's total capital stock, and firms between countries can access international knowledge at zero cost - that is, there is a productive externality in each country via international knowledge spillover. Growth rates between countries that are different also imply different growth rates of capital between countries, and then through international knowledge spillover the growth rates between countries will converge to be identical in a BGP. Thus, we examine the variation of growth rates between countries without overlooking the interdependence between countries. ${ }^{2}$

The existing literature always assumes no international difference in production technology and preference in the spirit of the Heckscher-Ohlin model in order to yield the identical long-run growth rates between countries. For example, Bond, Trask, and Wang (2003) and Doi, Nishimura,

\footnotetext{
${ }^{1}$ A two-country two-good endogenous growth model has the knife-edge problem. From the market clearing condition for international goods, the growth rates between the two countries need to be identical if BGP exists. However, in the traditional endogenous growth model the domestic growth rate is only determined by its own economy and is irrelevant to the foreign economy. Thus, the long-run growth rates between the two countries are impossible to be equal except when we make an assumption.

${ }^{2}$ Chen, Lee, and Shimomura (2009) introduce the endogenous rate of time preference and keep up with the "foreign" Joneses in their model in order to solve the knife-edge problem. Unfortunately, the set-up for the consumption externality is ad hoc.
} 
and Shimomura (2007) make the same assumption, as the former develops a two-country by three-good by two-factor endogenous growth model to examine the static and dynamic version of the Heckscher-Ohlin hypothesis, while the latter develops a two-country by two-good by two-factor endogenous growth model to discuss what jointly determines the long-run pattern of international trade and the long-run growth rate. Farmer and Lahiri (2005) assume perfect international mobility of capital and identical preference to produce the same long-run growth rates in a two-country by two-good by two-factor endogenous growth model with human capital externality.

The second main result herein is that there exists a unique and saddle-point BGP with both countries being incompletely specialized. Although the structure is parallel to the Ricardian model, there is a productive externality, which causes a diminishing marginal product of capital at the private level and, under free capital movement between the two sectors, complete specialization in one good cannot occur in this economy. Naito (2006b) obtains the same result in a small open economy.

The third main result is that a higher import tariff on the consumption good in the domestic country may boost (resp. reduce) the long-run economic growth rate when the foreign (resp. domestic) country has absolute advantage in the investment good. The intuition behind this may be explained as follows. If Home imports the consumption good, then a higher tariff on this good leads to a higher domestic price of this good and thereby the firms reallocate resources to this sector. Hence, the supply rise of the consumption good in the world market lowers the international price of this good and then Foreign's firms reallocate resources to the investment sector. With a diminishing marginal product of capital in the investment sector, the former effect results in a higher growth rate for Home and the latter effect results in a lower growth rate for Foreign. It also implies that Home's growth rate of capital (Home's investment) is greater than that for Foreign. Through international knowledge spillover, Foreign's firms absorb more knowledge than Home's, so that Home's growth rate decreases and Foreign's growth rate increases. Eventually, the growth rates between the two countries converge to be identical. When Foreign has absolute advantage in the investment good, its speed of convergence is greater than Home's speed and then the new long-run two-country growth rate exceeds the original one. As a result, the growth rate rises as a higher tariff.

The above result is consistent with the ambiguous relationship between a tariff and economic growth in the existing empirical literature. While some papers have documented a negative 
relationship (e.g., Edwards, 1992; Lee, 1993 and Harrison, 1996), some papers have found a positive relationship (e.g. O'Rourke, 2000; Irwin, 2002 and Yanikkaya, 2003). Clemens and Williamson (2004) confirm that high tariffs are associated with fast growth before World War II, but with slow growth thereafter. For theoretical papers, this result also echoes Naito (2006b) in a two-sector endogenous growth model of a small open economy and Grossman and Helpman (1990) and Rivera-Batiz and Romer (1991) in a R\&D endogenous growth model, although there are many studies that find a negative relationship (e.g. Jones and Manuelli, 1990; Easterly and Rebelo, 1993; Osang and Pereira, 1996; Ben-David and Loewy, 1998; Naito, 2006a).

The final main result is that a rise in the tariff rate by one country may improve long-run world welfare under some parameter spaces. Owing to the productive externality in each country's production functions via international knowledge spillover, the competitive market's equilibrium is not Pareto optimal and thus the tariff policy may improve world welfare. This sharply contrasts with the past literature. For example, in static models, Hatta and Fukushima (1979) show that a unilateral reduction in a tariff rate by one country or a proportional reduction in all tariff rates by all countries improves the welfare of the world in a many-country two-good economy, and Fukushima and Kim (1989) generalize the result to include the case of many goods and countries. Nakanishi (1993) further derives the necessary-sufficient conditions for the existence of a strictly welfare-improving tariff reform both with and without changes in an international lump-sum transfer of income.

Finally, for the international knowledge spillover, some studies in the literature have empirically investigated its importance though they do not differentiate between private-good knowledge spillover and a public-good one. For example, Coe and Helpman (1995) estimate through their sample of 22 industrialized countries that the shares of foreign $R \& D$ in the total elasticity effect are $60 \%$ in the 15 smaller countries and $20 \%$ in the G-7 countries. By contrast, Park (1995) in his analysis of aggregate data for ten OECD countries estimates that foreign R\&D accounts for about two thirds of the total effect of R\&D on productivity. Eaton and Kortum (1999) calculate that the part of productivity growth in 1988 that is due to foreign R\&D is between $74 \%$ and $89 \%$ in Germany, France, and the U.K., around 65\% for Japan, and about $40 \%$ for the United States. Keller (2002) estimates that between 1983 and 1995, the contribution of technology diffusion from G-5 countries is on average almost $90 \%$ of the total $R \& D$ effect on productivity in nine other OECD countries.

The structure of the paper is as follows. Section 2 sets up the basic model. Section 3 
analyzes the balanced growth path and transitional dynamics. Section 4 and Section 5 examine the relationship between an import tariff and growth and welfare, respectively. Finally, some concluding remarks are made in Section 6.

\section{The Basic Model}

There are two countries (Home and Foreign) and two goods in each country: a pure consumption good and a pure investment good. The two goods are respectively produced by two sectors with capital as the only private input. The capital may be thought of as a composite of various types of physical and human capital as outlined in Rebelo (1991). International knowledge spillovers are introduced in this economy, which further each country's productivity. The markets are competitive. Firms produce goods and make rental payments for capital input and distribute their profits to the households that own capital and firms. The households use the income to purchase the two goods. We also assume that the numbers of the households and firms are normalized to one, and thus each variable defined below expresses its aggregated value as well. The Home government imposes an ad-valorem import tariff on the consumption goods ${ }^{3}$ with the amount of tariff revenue transferring to the households in a lump-sum fashion. Following the tradition of Oniki and Uzawa, we assume that while the two goods are tradable, capital stock is not internationally mobile.

\subsection{Firms in the two countries}

There are two sectors to produce each good with capital, $k_{i}$, as the only private input in each country. Following Arrow (1962) and Romer (1986), each firm's knowledge creation is a side product of investment, i.e. learning by doing, and knowledge is a public good that any other firms can access at zero cost, i.e. knowledge spillover. The former indicates that knowledge in each sector may be represented by the sector-specific capital, $k_{i}$, and the latter indicates that economy-wide knowledge is analogous to a productive externality.

Firms' new knowledge instantaneously spills over across sectors as well as within each sector. Drugeon and Venditti (2001), Nishimura and Venditti (2002), Drugeon et al. (2003), and Naito (2006b) already employ the intersectoral spillover. Under this set-up, the externality may include the intersectoral spillover and may be represented by total capital, $k$. Through international trade,

\footnotetext{
${ }^{3}$ If we assume the government imposes an import tariff on the investment good, then the main result is also similar.
} 
the new knowledge also instantaneously spills over across different countries. ${ }^{4}$ Thus, the externality may be represented by total capital in both countries, i.e. $k$ and $k^{*}$.

For simplicity and a clear-cut solution, abstracting from domestic knowledge spillover, Home's productive externality is just represented by Foreign's total capital stock, $k^{*} .5$ Thus, the production function of good $i$ in the Home country is:

$$
y_{i}=a_{i} k_{i}^{1-\alpha} \bar{k}^{* \alpha}, \quad i=1,2,
$$

where $i=1$ (resp. 2) corresponds to the consumption (resp. investment) good, $\bar{k}^{*}$ is Foreign's total capital which stands for the productive externality, and $\bar{k}^{*}=k^{*}$ in the equilibrium. Parameter $a_{i}$ is the productivity coefficient in sector $i$, and $\alpha$ measures the productivity of international knowledge spillover which is identical between the two sectors. As for the knowledge spillover effect, it may also be represented by total capital stock at the world level $\left(\bar{k}+\bar{k}^{*}\right)$. However, under this formulation, there is no analytical solution for the comparative statics in Section 4. That is why we employ the set-up in Equation 1.

While the two sectors display decreasing returns at the private level, the sector exhibits constant returns at the social level due to an externality that is ignored by infinitesimal firms. One implication of decreasing private returns is positive profits. Unless the number of firms is fixed, we must assume that there is a fixed entry cost to determine the number of firms along the equilibrium paths. As is clear from below, the external effects and the degree of decreasing returns required for the two-country equilibrium may be arbitrarily small and generate only a small amount of profits, and thereby a small fixed cost of entry is sufficient to deter new entrants. To solve this problem, we follow Benhabib, et al (2000), Mino (2001), and Doi, Nishimura, and Shimomura (2007) to assume that the profits are distributed back to the households that own these firms.

The full employment conditions are:

$$
k=k_{1}+k_{2} \text {, }
$$

where $k$ is the total capital stock.

Suppose that the government in the Home country imposes an ad-valorem import tariff,

\footnotetext{
4 Although there is a lot of international technology diffusion whose marginal cost of use is not zero, we only focus on the public-good type for simplicity. The required proportion for this kind of international knowledge spillover may be arbitrarily small, and then this set-up is quite reasonable.

${ }^{5}$ If the knowledge spillover is from both domestic firms and foreign firms, then the externality can be written by a Cobb-Douglas form, $k^{1-\beta} k^{* \beta}$, where $\beta$ is the share of international knowledge spillover. In this setting, the main results are similar. Therefore, we just examine the special case when $\beta=1$.
} 
denoted as $\tau$, on the consumption goods and then the domestic prices of the pure consumption good become $p(1+\tau)$, where $p$ is the international price of the consumption good in terms of the investment good. Given $p, \tau$, and the rental rate of capital, $r$, if the Home country produces both goods simultaneously, then the first-order conditions for the representative competitive firm in each sector are respectively:

$$
\begin{aligned}
& (1-\alpha) p(1+\tau) \frac{y_{1}}{k_{1}}=r, \\
& (1-\alpha) \frac{y_{2}}{k_{2}}=r,
\end{aligned}
$$

where $r$ is also the interest rate if we assume that there is no depreciation of capital.

Suppose Foreign has a similar production structure without an import tariff. Denote the variables with an asterisk as in Foreign, except the productivity parameter of international knowledge spillover changes to $\eta$ from $\alpha$. Thus, the production function of good $i$ in the Foreign country is:

$$
y_{i}^{*}=a_{i}^{*} k_{i}^{* 1-\eta} \bar{k}^{\eta}, \quad i=1,2 .
$$

Similarly the first-order conditions for the Foreign's representative firm are:

$$
\begin{aligned}
& (1-\eta) p \frac{y_{1}^{*}}{k_{1}^{*}}=r^{*}, \\
& (1-\eta) \frac{y_{2}^{*}}{k_{2}^{*}}=r^{*}
\end{aligned}
$$

\subsection{Households in the two countries}

Home's representative household earns factor income with $k(0)$ units of capital endowed initially, profit from the two firms, and a lump-sum transfer from the government in order to purchase the two goods. The household's budget constraint is thus:

$$
r k+\pi+T=p(1+\tau) c+I,
$$

where $\pi=\pi_{1}+\pi_{2}=\left[p(1+\tau) y_{1}-r k_{1}\right]+\left(y_{2}-r k_{2}\right)$ is the profit from the two firms, $T$ is the lump-sum transfer, $c$ is consumption, and $I$ is investment. The law of motion for capital accumulation is:

$$
\dot{k}=I \text {. }
$$

For simplicity, no depreciation in capital is assumed.

Given $r, p, \tau, T$, and $k(0)$, the representative agent's problem is to choose $c, I$, and $k$ to 
maximize the following discounted lifetime utility:

$$
U=\int_{0}^{\infty} u(c) e^{-\rho t} d t,
$$

subject to (5) and (6). Parameter $\rho>0$ is the rate of time preference. For simplicity, following Ventura (1997), we assume the felicity has logarithmic form:

$$
u(c)=\ln c .
$$

To solve the household's optimization problem, we set up the current-value Hamiltonian:

$$
H=\ln c+\lambda[r k+\pi+T-p(1+\tau) c],
$$

where $\lambda$ is the co-state variable of capital. The necessary conditions for optimality are then:

$$
\begin{aligned}
& \frac{1}{c}=\lambda p(1+\tau), \\
& \lambda r=\rho \lambda-\dot{\lambda},
\end{aligned}
$$

with the transversality conditions $\lim _{t \rightarrow \infty} \lambda k e^{-\rho t}=0$. While condition (9a) represents that marginal benefit is equal to marginal cost for consumption condition, (9b) presents Euler equations for capital.

The behavior of Foreign's household is the same without an import tariff. Thus, the first-order condition for the household is parallel to (9a) and (9b) with asterisked variables and without a tariff. Moreover, for simplicity, we assume the rate of time preferences between these two countries are the same as follows.

$$
\rho=\rho^{*} .
$$

\subsection{Government in the two countries}

Suppose that the government in the Home country imposes an ad-valorem import tariff on the consumption goods with the amount of tariff revenue transferring to the households in a lump-sum fashion. Thus, the government budget constraint is:

$$
T=\tau p\left(c-y_{1}\right) .
$$

Nothing is done by the government in the Foreign country.

\section{Two-country World Market Equilibrium}

For free trade, the world commodity market-clearing condition for the consumption goods is:

$$
c+c^{*}=y_{1}+y_{1}^{*} \text {. }
$$


Once (11) is satisfied, the world market for the investment goods is automatically cleared.

We are now ready to analyze the equilibrium. The equilibrium is a path $\left\{y_{1}, y_{2}, y_{1}^{*}, y_{2}^{*}, c, c^{*}\right.$, $\left.k, k^{*}, k_{1}, k_{2}, k_{1}^{*}, k_{2}^{*}, I, I^{*}, r, r^{*}, p, \lambda, \lambda^{*}, T\right\}$ and is determined by (1)-(6), (9)-(11) and Foreign's counterpart of (1)-(2), (5)-(6), and (9).

\subsection{Transformation of the economic system}

In order to analyze the equilibrium, it is necessary to transform the equilibrium conditions with perpetual growth into a system with stationary variables. Denote $n=k^{*} / k, m=p c / k, m^{*}=p c^{*} / k^{*}$, $v=k_{1} / k$, and $v^{*}=k_{1} * / k^{*}$. In what follows we briefly explain the transformation.

First, multiplying (11) by $p / k$ and utilizing (1), (2), and (3a)-(4b), the world market-clearing condition may be rewritten as:

$$
m+m^{*} n=\frac{a_{2}}{1+\tau}\left(\frac{n}{1-v}\right)^{\alpha} v+a_{2}^{*}\left[\frac{1}{\left(1-v^{*}\right) n}\right]^{\eta} v^{*} n .
$$

Next, (3a)-(3b) and (4a)-(4b) can be solved to yield the relationship between $v$ and $v^{*}$.

$$
\left(\frac{v}{1-v}\right)^{\alpha}=\frac{(1+\tau) a_{1} a_{2}^{*}}{a_{1}^{*} a_{2}}\left(\frac{v^{*}}{1-v^{*}}\right)^{\eta}
$$

This implies that Home's fraction of capital allocated to the consumption sector and Foreign's fraction are positively related with $\frac{d v^{*}}{d v}=\frac{\alpha v^{*}\left(1-v^{*}\right)}{\eta v(1-v)}>0$. If $\alpha=\eta$, then $v>v^{*}$ when Home has a comparative advantage in the pure consumption good $\left[(1+\tau) a_{1} / a_{2}>a_{1} * / a_{2} *\right]$ and $v<v *$ when Home has a comparative advantage in the pure investment good $\left[(1+\tau) a_{1} / a_{2}<a_{1} * / a_{2} *\right]$.

Differentiating (9a) and using (3b) and (9b) lead to the following growth rate of consumption.

$$
\frac{\dot{c}}{c}=(1-\alpha) a_{2}\left(\frac{n}{1-v}\right)^{\alpha}-\rho-\frac{\dot{p}}{p} \text {. }
$$

Based on (5) and using (3a)-(3b) and (10), we get the growth rate of capital:

$$
\frac{\dot{k}}{k}=a_{2}\left(\frac{n}{1-v}\right)^{\alpha}\left[1-\frac{\tau v}{1+\tau}\right]-m .
$$

The growth rate of $m$ can be derived by (14a) and (14b) as follows.

$$
\frac{\dot{m}}{m}=\frac{\dot{p}}{p}+\frac{\dot{c}}{c}-\frac{\dot{k}}{k}=m-a_{2}\left(\frac{n}{1-v}\right)^{\alpha}\left[\alpha-\frac{\tau v}{1+\tau}\right]-\rho .
$$

Moreover, the counterpart in the foreign country is: 


$$
\frac{\dot{m}^{*}}{m^{*}}=\frac{\dot{p}}{p}+\frac{\dot{c}^{*}}{c^{*}}-\frac{\dot{k}^{*}}{k^{*}}=m^{*}-\eta a_{2}^{*}\left[\frac{1}{\left(1-v^{*}\right) n}\right]^{\eta}-\rho .
$$

Finally, with the help of (14b), the growth rate of $n$ is:

$$
\frac{\dot{n}}{n}=\frac{\dot{k} *}{k^{*}}-\frac{\dot{k}}{k}=a_{2}^{*}\left[\frac{1}{\left(1-v^{*}\right) n}\right]^{\eta}-a_{2}\left(\frac{n}{1-v}\right)^{\alpha}\left[1-\frac{\tau v}{1+\tau}\right]+m-m^{*} .
$$

The dynamics of the system can therefore be described by (12)-(13) and (15)-(17), which determine the equilibrium paths of five variables: $m, m^{*}, n, v$, and $v^{*}$. Other variables are solved by other equations.

\subsection{Balanced growth path}

We now analyze the equilibrium in a steady state. A steady state is a perfect foresight equilibrium with a BGP under which $m, m^{*}, n, v$, and $v^{*}$ are constant, and thus $\dot{n} / n=\dot{m} / m=\dot{m}^{*} / m^{*}=0$. Denote $\tilde{n}, \tilde{m}, \tilde{m}^{*}, \tilde{v}$, and $\tilde{v}^{*}$ as the values in a BGP. Based on (15) and (16), we then obtain:

$$
\begin{aligned}
& \tilde{m}=a_{2}\left(\frac{\tilde{n}}{1-\tilde{v}}\right)^{\alpha}\left[\alpha-\frac{\tau v}{1+\tau}\right]+\rho, \\
& \tilde{m}^{*}=\eta a_{2}^{*}\left[\frac{1}{\left(1-\tilde{v}^{*}\right) \tilde{n}}\right]^{\eta}+\rho .
\end{aligned}
$$

Utilizing (18a) and (18b), Equation (17) implies that the rates of economic growth between these two countries are identical.

$$
(1-\alpha) a_{2}\left(\frac{\tilde{n}}{1-\tilde{v}}\right)^{\alpha}-\rho=(1-\eta) a_{2}^{*}\left[\frac{1}{\left(1-\tilde{v}^{*}\right) \tilde{n}}\right]^{\eta}-\rho .
$$

This equation is the main difference from the existing literature. After $\tilde{v}$ and $\tilde{v}^{*}$ are determined, the growth rates between countries may be different. Thanks to international knowledge spillover, $\tilde{n}$ appears in both Home's and Foreign's growth rates. The two growth rates may now converge to be identical through the adjustment of $\tilde{n}$ - that is, (19a) can determine the value of $\tilde{n}$. The past literature, such as Bond, Trask, and Wang (2003) and Doi, Nishimura and Shimomura (2007), always assumes no international difference in production technology and preference, such that this equation is met automatically.

Using (18a) and (18b), the world market-clearing condition can be rewritten by: 


$$
\rho+\rho \tilde{n}=a_{2}\left(\frac{\tilde{n}}{1-\tilde{v}}\right)^{\alpha}(\tilde{v}-\alpha)+a_{2}^{*}\left[\frac{1}{\left(1-\tilde{v}^{*}\right) \tilde{n}}\right]^{\eta} \tilde{n}\left(\tilde{v}^{*}-\eta\right) .
$$

Since the left-hand side is positive, we need to require $\tilde{v}>\alpha$ and $\tilde{v}^{*}>\eta$ for a positive left-hand side. Thus, $\tilde{n}, \tilde{v}$, and $\tilde{v}^{*}$ can be solved by the system of (13), (19a), and (19b).

We next assess the existence of $\tilde{n}, \tilde{v}$, and $\tilde{v}^{*}$. Based on (13), we find that $\tilde{v}^{*}=\tilde{v}^{*}(\tilde{v})$. Moreover, given $\tilde{v}$, , (19a) can determine a unique $\tilde{n}=\tilde{n}(\tilde{v})=\left[\frac{(1-\eta) a_{2} *}{(1-\alpha) a_{2}} \frac{(1-v)^{\alpha}}{\left(1-v^{*}\right)^{n}}\right]^{\frac{1}{\alpha+\eta}} \quad$ with $\frac{d \tilde{n}}{d \tilde{v}}=\frac{\alpha \tilde{n}(\tilde{\hat{v}} *-\tilde{v})}{(\alpha+\eta) \tilde{v}(1-\tilde{v})}$. As a result, (19b) is a function of $\tilde{v}$ and may determine $\tilde{v}$. We rearrange $(19 \mathrm{~b})$ as follows.

$$
a_{2}\left(\frac{\tilde{n}(\tilde{v})}{1-\tilde{v}}\right)^{\alpha}(\tilde{v}-\alpha)+a_{2}^{*}\left\{\frac{1}{\left[1-\tilde{v}^{*}(\tilde{v})\right] \tilde{n}(\tilde{v})}\right\}^{\eta} \tilde{n}(\tilde{v})\left[\tilde{v}^{*}(\tilde{v})-\eta\right]-\rho \tilde{n}(\tilde{v})=\rho .
$$

We find that the left-hand side (LHS) of (20) is increasing in $\tilde{v}$ if $\tilde{v}>\alpha, \tilde{v}^{*}>\eta$. (see Appendix A). In addition, $L H S \rightarrow \infty$ as $\tilde{v} \rightarrow 1$ and $L H S \rightarrow-\rho \tilde{n}(\tilde{v}=0)<0$ as $\tilde{v} \rightarrow 0$. Consequently, $\tilde{v}$ can be determined uniquely by (20) as depicted in Figure 1.

\section{[Insert Figure 1 here]}

One of the preconditions, $\tilde{v}>\alpha$, corresponds to $\operatorname{LHS}(\tilde{v}=\alpha)<\rho$, and together with the other precondition, $\tilde{v}^{*}>\eta$, we obtain the following condition for a unique $\alpha<\tilde{v}<1$. Condition S: $\quad \eta<\frac{1}{1+\Omega}<\eta+\frac{\rho}{a_{2}^{*}}(1-\alpha)^{\frac{(1-\alpha)(1-\eta)}{\alpha+\eta}}(1-\eta)^{\frac{-(1-\eta)}{\alpha+\eta}}\left(\frac{\Omega}{1+\Omega}\right)^{\frac{\eta(1-\alpha)}{\alpha+\eta}}$, where $\Omega \equiv\left(\frac{(1+\tau) a_{1} a_{2}^{*}}{a_{1}^{*} a_{2}}\right)^{\frac{1}{\eta}}\left(\frac{1-\alpha}{\alpha}\right)^{\frac{\alpha}{\eta}}$. Other thing being equal, Condition $S$ indicates that the gap between $a_{2}$ and $a_{2} *$ is limited. Given $\tilde{v}, \quad \tilde{n}>0$ and $\eta<\tilde{v}^{*}<1$ can be solved by (19b) and (13), respectively. In sum, we get the following proposition.

Proposition 1 Under Condition $S$ and an identical rate of time preference between Home and Foreign, BGP is uniquely determined with incomplete specialization in each country.

Why do we obtain the result of incomplete specialization in each country in a two-sector AK endogeneous growth model? Although the production functions are linear and parallel to the Ricardian model, there is externality in the production functions. This externality leads to a diminishing marginal product of capital at the private level. Since capital can move freely 
between these two sectors, the marginal products of capital between the two sectors need to be identical in equilibrium. Consequently, complete specialization in one good cannot occur in this economy. This result is the same as Naito (2006b) in a small open economy.

\subsection{Transitional Dynamics}

The dynamics of the system are described by (12)-(13) and (15)-(17), which determine the equilibrium paths of five variables: $m, m^{*}, n, v$, and $v^{*}$. Now we simplify this system. Under $\alpha=\eta$, Equation (12) and (13) indicate that $v$ and $v^{*}$ are the functions of $m, m^{*}$, and $n$, as follows.

$$
\begin{aligned}
& v=v\left(m, m^{*}, n\right), \\
& v^{*}=v^{*}\left(m, m^{*}, n\right),
\end{aligned}
$$

with $\frac{\partial v}{\partial m}=\frac{1}{\Phi_{1}}, \frac{\partial v}{\partial m^{*}}=\frac{n}{\Phi_{1}}, \frac{\partial v}{\partial n}=\frac{m^{*}-\frac{y_{2}}{k_{2}} \frac{\alpha v}{(1+\tau) n}-\frac{y_{2}^{*}}{k_{2}^{*}}(1-\alpha) v^{*}}{\Phi_{1}}$

$$
\frac{\partial v^{*}}{\partial m}=\frac{\Phi_{2}}{\Phi_{1}}, \frac{\partial v^{*}}{\partial m^{*}}=\frac{n \Phi_{2}}{\Phi_{1}}, \frac{\partial v^{*}}{\partial n}=\frac{\Phi_{2}\left[m^{*}-\frac{y_{2}}{k_{2}} \frac{\alpha v}{(1+\tau) n}-\frac{y_{2}^{*}}{k_{2}^{*}}(1-\alpha) v^{*}\right]}{\Phi_{1}}
$$

where $\Phi_{1}=\frac{\alpha v+1-v}{(1+\tau)(1-v)} \frac{y_{2}}{k_{2}}+\frac{v^{*} n\left(\alpha v^{*}+1-v^{*}\right)}{v(1-v)} \frac{y_{2}^{*}}{k_{2}^{*}}$, and $\Phi_{2}=\frac{v^{*}\left(1-v^{*}\right)}{v(1-v)}$. As a result, this system is reduced to a $3 \times 3$ system that is described by (15)-(17) and determines three variables: $m, m^{*}$, and $n$.

To investigate the local dynamics of the system, we take a linear Taylor's expansion of (15)-(17) in the neighborhood of the unique BGP. The expansion leads to:

$$
\left(\begin{array}{c}
\dot{m} \\
\dot{m} * \\
\dot{n}
\end{array}\right)=\left(\begin{array}{lll}
J_{11} & J_{12} & J_{13} \\
J_{21} & J_{22} & J_{23} \\
J_{31} & J_{32} & J_{33}
\end{array}\right)\left(\begin{array}{c}
m-\tilde{m} \\
m *-\tilde{m}^{*} \\
n-\tilde{n}
\end{array}\right),
$$

where $J_{11}=\tilde{m}\left\{1-\frac{1-\tilde{v}}{\Phi_{3}}\left[\left(\alpha-\frac{\tau \tilde{v}}{1+\tau}\right) \frac{\alpha}{1-\tilde{v}}-\frac{\tau}{1+\tau}\right]\right\}$,

$$
\begin{aligned}
& J_{12}=-\frac{\tilde{m} n(1-\tilde{v})}{\Phi_{3}}\left[\left(\alpha-\frac{\tau \tilde{v}}{1+\tau}\right) \frac{\alpha}{1-\tilde{v}}-\frac{\tau}{1+\tau}\right], \\
& J_{13}=-\tilde{m} \frac{y_{2}}{k_{2}}\left\{\alpha\left(\alpha-\frac{\tau \tilde{v}}{1+\tau}\right)\left[\frac{1}{\tilde{n}}+\frac{\Phi_{4}}{\Phi_{3}}\right]-\frac{\tau}{1+\tau} \frac{(1-\tilde{v}) \Phi_{4}}{\Phi_{3}}\right\}, \\
& J_{21}=-\frac{\alpha^{2} \tilde{\tilde{m}}^{*} v^{*}}{\tilde{\bar{v}} \Phi_{3}}<0, \\
& J_{22}=\tilde{m} *\left[1-\frac{\alpha^{2} \tilde{\hat{v}} * \tilde{\tilde{n}}}{\Phi_{3}}\right],
\end{aligned}
$$




$$
\begin{aligned}
& J_{23}=-\tilde{m} * \alpha^{2} \frac{y_{2}}{k_{2}}\left[\frac{\tilde{v}^{*} \Phi_{4}}{\nu \Phi_{3}}-\frac{1}{\tilde{n}}\right], \\
& J_{31}=\tilde{n}\left\{\frac{\alpha \tilde{v}^{*}}{\Phi_{3} \tilde{v}}-\frac{1-\tilde{v}}{\Phi_{3}}\left[\left(1-\frac{\tau \tilde{v}}{1+\tau}\right) \frac{\alpha}{1-\tilde{v}}-\frac{\tau}{1+\tau}\right]+1\right\}, \\
& J_{32}=\tilde{n}\left\{\frac{\alpha \tilde{v} * \tilde{n}}{\Phi_{3} \tilde{v}}-\frac{(1-\tilde{v} \tilde{n}}{\Phi_{3}}\left[\left(1-\frac{\tau \tilde{v}}{1+\tau}\right) \frac{\alpha}{1-\tilde{v}}-\frac{\tau}{1+\tau}\right]-1\right\}, \\
& J_{33}=\tilde{n} \frac{y_{2}}{k_{2}}\left\{\frac{\alpha \tilde{v} * \Phi_{4}}{\Phi_{3} \tilde{v}}-\frac{\alpha}{\tilde{n}}-\left(1-\frac{\tau \tilde{v}}{1+\tau}\right)\left(\frac{\alpha}{1-\tilde{v}}+\frac{\alpha \Phi_{4}}{\Phi_{3}}\right)+\frac{\tau}{1+\tau} \frac{(1-\tilde{v}) \Phi_{4}}{\Phi_{3}}\right\},
\end{aligned}
$$

with $\Phi_{3}=\frac{\alpha \tilde{v}+1-\tilde{v}}{(1+\tau)}+\frac{\tilde{v} * \tilde{n}\left(\alpha \tilde{\nu}^{*}+1-\tilde{v}^{*}\right)}{\tilde{v}}, \quad \Phi_{4}=\alpha+\rho \frac{k_{2}}{y_{2}}-\frac{\alpha \tilde{v}}{(1+\tau) \tilde{n}}-(1-\alpha) \tilde{v}^{*}$.

The Jacobean matrix in (22), denoted as $J$, determines the local dynamic properties of the economical system. The $3 \times 3$ system includes a state-like variable, whose initial value $n(0)$ is predetermined, and two control-like variables, $m$ and $m^{*}$, which adjust instantaneously. Therefore, if the Jacobean matrix has two, or a larger number of, eigenvalues with negative real parts, then the equilibrium path near the unique BGP is locally indeterminate.

Because the trace, the determinant of the Bordered Hessian, and the determinant of matrix $J$ are complicated and non-analytical, we unfortunately cannot investigate the signs of eigenvalues based on the Routh-Hurwitz theorem. We instead use a numerical approach to find the eigenvalues.

\section{[Insert Table 1 here]}

Table 1 summarizes the benchmark parameter values for simulation. First, the time preference rate is chosen at $\rho=0.025$ in accordance with Benhabib and Perli (1994). Second, we set a relative small value of the degree of externality at $\alpha=\eta=0.05$. Third, since U.S. trade-weighted average tariffs for the rest of the world in 2001 are about $1.64 \%$, we choose $\tau=0.0167$. Fourth, without loss of generality, we normalize the parameter values of the productivity coefficient in Sector $y_{1}$ by $a_{1}=1$ and of the initial value of capitals in the both countries by $k_{0}=1=k_{0} *$. Parameters $a_{2}$ and $a_{2} *$ are chosen at the range of [0,4]. Finally, in accordance with $(1+\tau) a_{1} / a_{2}<a_{1} * / a_{2} *$, we set $a_{1} *=(1+\tau) a_{1} a_{2} * / a_{2}+0.02$.

Our simulation results indicate that the unique BGP is a saddle point under the benchmark parameter values - that is, local indeterminacy does not emerge. We further broaden the spaces of parameter values to assure the robustness of the above quantitative results. We find that under a large range of parameter values for $\rho=\rho^{*} \in[0.01,0.06], \alpha=\eta \in[0.01,0.20], \quad$ and $a_{1} * \in\left[(1+\tau) a_{1} a_{2} * / a_{2}+0.01,(1+\tau) a_{1} a_{2} * / a_{2}+0.10\right]$, the dynamic equilibrium path toward unique BGP 
is also locally determinate. It means that the three imperfect competitive mechanisms behind this model, which are import tariff, knowledge spillover effect, and international immobile capital stock, are not strong enough to establish local indeterminacy.

\section{Import Tariff and Growth}

This section examines the long-run relationship between import tariffs and growth. Based on (13), (19a), and (19b), we totally differentiate these three equations to obtain the tariff effect on $\tilde{n}, \tilde{v}$, and $\tilde{v}^{*}$. (See Appendix B for a more detailed derivation.)

$$
\begin{aligned}
& \frac{d \tilde{v}}{d \tau}=\frac{1}{\Delta(1+\tau)}\left\{\frac{\eta}{1-\tilde{v}^{*}}\left[\frac{\alpha}{\tilde{n}}+\frac{(1-\alpha)\left(\tilde{v}^{*}-\eta\right)}{\Lambda}-\frac{1}{1+\tilde{n}}\right]+\frac{(\alpha+\eta)(1-\alpha)}{\Lambda}\right\}>0, \\
& \frac{d \tilde{v}^{*}}{d \tau}=\frac{-1}{\Delta(1+\tau)}\left\{\frac{\alpha+\eta}{n} \frac{1-\eta}{\Lambda}+\frac{\alpha}{1-\tilde{v}}\left[\frac{\eta}{\tilde{n}}+\frac{1}{1+\tilde{n}}-\frac{(1-\alpha)\left(\tilde{v}^{*}-\eta\right)}{\Lambda}\right]\right\}<0, \\
& \frac{d \tilde{n}}{d \tau}=\frac{-1}{\Delta(1+\tau)}\left\{\frac{\alpha}{1-\tilde{v}} \frac{(1-\alpha) \tilde{n}}{\Lambda}+\frac{\eta}{1-\tilde{v}^{*}}\left[\frac{\alpha}{1-\tilde{v}}+\frac{1-\eta}{\Lambda}\right]\right\}<0,
\end{aligned}
$$

where $\Lambda \equiv(\tilde{v}-\alpha)(1-\eta)+(1-\alpha) \tilde{n}\left(\tilde{v}^{*}-\eta\right)>0$ and

$$
\Delta \equiv \frac{\eta}{\tilde{v}^{*}\left(1-\tilde{v}^{*}\right)}\left[\frac{\alpha}{1-\tilde{v}}\left(\frac{1}{1+\tilde{n}}+\frac{\eta}{\tilde{n}}-\frac{(1-\alpha)\left(\tilde{v}^{*}-\eta\right)}{\Lambda}\right)+\frac{\alpha+\eta}{\tilde{n}} \frac{1-\eta}{\Lambda}\right]+\frac{\alpha}{\tilde{v}(1-\tilde{v})}\left[\frac{\eta}{1-\tilde{v}^{*}}\left(\frac{\alpha}{\tilde{n}}+\frac{(1-\alpha)\left(\tilde{v}^{*}-\eta\right)}{\Lambda}-\frac{1}{1+\tilde{n}}\right)+\frac{(1-\alpha)(\alpha+\eta)}{\Lambda}\right]>0 .
$$

According to (19a), Home's growth rate, denoted as $g$, is:

$$
g=(1-\alpha) a_{2}\left(\frac{\tilde{n}}{1-\tilde{v}}\right)^{\alpha}-\rho
$$

Under $\alpha=\eta$, the only possibility for Home to import the pure consumption good is that Home has a comparative advantage in the pure investment good, i.e. $(1+\tau) a_{1} / a_{2}<a_{1} * / a_{2} *{ }^{6}$ Utilizing (23a) and (23c), the tariff effect on the growth rate is then:

$$
\frac{d g}{d \tau}=\frac{(g+\rho) \alpha \eta(1-\alpha)}{\Delta(1+\tau) \tilde{n}(1+\tilde{n})\left(1-\tilde{v}^{*}\right) \Lambda}\left\{\left(\frac{a_{2}^{*}}{a_{2}}\right)^{\frac{1}{\alpha}}-1\right\} \geq 0 \text { if } a_{2}^{*}<a_{2} .
$$

This implies that a higher tariff raises the growth rate if Foreign has an absolute advantage in the pure investment good, i.e. $a_{2}{ }^{*}>a_{2}$. It also follows $a_{1} *>(1+\tau) a_{1} a_{2} * / a_{2}>a_{1}$, which means that Foreign has an absolute advantage in the pure consumption good.

The intuition may be explained as follows. A higher tariff makes the domestic price of the pure consumption good higher and thereby the resources reallocated to the consumption sector

\footnotetext{
${ }^{6}$ Please see Appendix C, which shows this condition.
} 
from the investment sector, i.e. $\tilde{v}$, increase. This effect causes a rise in the supply of the pure consumption good in the world market and then a lower international price of the pure consumption good. Thus, Foreign reallocates resources to the investment sector from the consumption sector, i.e. $\tilde{v}^{*}$ decreases. With diminishing marginal product of capital, the increase in $\tilde{v}$ induces a higher domestic marginal product of capital in the pure investment sector and the decrease in $\tilde{v}^{*}$ induces a lower foreign marginal product of capital.

It follows that Home's growth rate is greater than Foreign's rate. Under BGP, it also implies that Home's growth rate of capital (Home's investment) is greater than Foreign's rate. By international knowledge spillover, Foreign firms absorb more knowledge than Home firms, such that Home's growth rate decreases and Foreign's growth rate increases - that is, $\tilde{n}$ drops to narrow down the difference between the two-country growth rates. Eventually, the growth rates between the two countries converge to be identical. Under $a_{2} *>a_{2}$, Foreign's speed of convergence is greater than Home's speed and then the new long-run two-country growth rate exceeds the original one. As a result, the growth rate rises as a higher tariff. On the contrary, under $a_{2} *<a_{2}$, the reverse is true. To sum up, we get the following proposition.

Proposition 2. Suppose that Home and Foreign differ only in relative productivity. The import tariff on the pure consumption good raises (reduces) the economic growth rate if Foreign (Home) has an absolute advantage in the pure investment good.

\section{Import Tariff and Welfares in Both Countries}

Now we turn to examining the relationship between import tariff and long-run welfares in both countries. As is clear from below, a higher tariff may simultaneously raise the welfares in both countries under some parameter spaces.

\subsection{Welfare in Home country}

This section analyzes Home's welfare. Under BGP, the representative agent's lifetime utility is:

$$
U=\int_{0}^{\infty} u(c) e^{-\rho t} d t=\frac{1}{\rho}\left(\ln c_{0}+\frac{g}{\rho}\right)
$$

where $c_{0}=\frac{\tilde{m} k_{0}}{\tilde{p}}=\frac{k_{0} a_{1}^{*}}{a_{2}^{*}}\left(\frac{1-\tilde{\mathcal{V}}^{*}}{\tilde{\tilde{v}}^{*}}\right)^{\eta}\left\{a_{2}\left(\frac{\tilde{n}}{1-\tilde{v}}\right)^{\alpha}\left(\alpha-\frac{\tau \tilde{v}}{1+\tau}\right)+\rho\right\}$, which is the initial value of consumption in 
the Home country and represents the present consumption, and $g$ is the long-run growth rate, which represents future consumption. It indicates that the welfare is increasing in $c_{0}$ and $g$.

Since it is difficult to conduct a welfare analysis of government policy in the same way as in the previous section, we instead use a numerical approach to investigate the welfare effect of a tariff below. For simplicity and in accordance with Home importing the pure consumption good, we assume that both countries are identical in every aspect except for the relative productivity, i.e. $\alpha=\eta, \rho=\rho^{*}$, and $(1+\tau) a_{1} / a_{2}<a_{1} * / a_{2} *$. The parameter values for simulation are also followed by Table 1. For the tariff policy, we assume that government raises the tariff rate from 0.01 to 0.02 .

Under the benchmark parameter spaces, we find that a tariff reduces the initial consumption, $c_{0}$. This relationship can also be assessed by (9a) in the sense that a higher tariff leads to a higher domestic price of the pure consumption good, $p(1+\tau)$, and then to lower demand for the pure consumption good. It appears that the only way to raise welfare is that the growth rate must be lifted by a higher tariff and this effect must be greater than that of the drop in initial consumption.

[Insert Figure 2 here]

We find it possible to get better welfare under a tariff policy. In Figure 2 we simulate the region in the $\left(a_{2}, a_{2} *\right)$ plane separating a better-off area and worse-off area, with the shaded area exhibiting a better welfare. Two observations are in order. First, $a_{2} *$ needs to be greater than $a_{2}$, which implies a higher long-run growth rate under a tariff policy. Second, the difference between $a_{2}$ and $a_{2} *$ is limited to Condition $\mathrm{S}$ for the existence of a steady state, and hence the gap between $a_{2}$ and $a_{2}{ }^{*}$ should be not too large. That is why these two parameters are positively correlated.

\subsection{Welfare in Foreign country}

We analyze Foreign's welfare in this section. Under BGP, the representative agent's lifetime utility is:

$$
U^{*}=\frac{1}{\rho}\left(\ln c_{0}^{*}+\frac{g^{*}}{\rho}\right)=\frac{1}{\rho}\left(\ln c_{0}^{*}+\frac{g}{\rho}\right),
$$

where $c_{0}^{*}=\frac{\tilde{m}^{*} k_{0}^{*}}{\tilde{p}}=\frac{k_{0}^{*} a_{1}^{*}}{a_{2}^{*}}\left(\frac{1-\tilde{v}^{*}}{\tilde{v}^{*}}\right)^{\eta}\left\{\eta a_{2}^{*}\left[\frac{1}{\left(1-\tilde{v}^{*}\right) \tilde{n}}\right]^{\eta}+\rho\right\}$, which is the initial value of consumption in the Foreign country. Under the benchmark parameter spaces, we also find a region for better Foreign welfare under Home's tariff policy.

\section{[Insert Figure 3 here]}

Figure 3 presents the counterpart of welfare analysis in Foreign. Two observations are in order. First, the region for better welfare in Figure 3 contains that in Figure 2. Thus, there exists 
a region whereby the welfares in both countries rise simultaneously under a higher tariff in Home. Second, even if $a_{2} *$ is smaller than $a_{2}$, i.e. a lower Foreign growth rate, Foreign's welfare may rise. The reason is that the drop in the international price may lead to a higher initial consumption.

Owing to the productive externality in the production functions in each country via international knowledge spillover, the equilibrium in the competitive market is not Pareto optimal, and the tariff policy may thus improve the world welfare. This result is in sharp contrast with the past literature. For example, Hatta and Fukushima (1979) show that a unilateral reduction in a tariff rate by one country or a proportional reduction in all tariff rates by all countries improves the welfare of the world in a many-country two-commodity static model. Fukushima and Kim (1989) generalize the result to include the case of many commodities and countries. Nakanishi (1993) further derives necessary-sufficient conditions for the existence of a strictly welfare-improving tariff reform both with and without changes in international lump-sum transfer of income.

In order to assure the robustness of the above quantitative results, we finally conduct some sensitivity analysis (Table 2). In the analysis, we change the value of one parameter from the benchmark case while keeping the values of all other parameters unchanged. We have experimented using a higher and a lower time preference rate $(\rho)$, a productivity coefficient of the foreign country in the consumption good sector $\left(a_{1}^{*}\right)$, and a knowledge spillover effect $(\alpha=\eta)$. Table 2 also presents the lowest and highest points of the region for better welfare. In most cases, the results for better world welfare are quantitatively similar to those in Figures 1 and 2. As for parameters $a_{1}^{*}$ and $\alpha(=\eta)$, two remarks are in order.

\section{[Insert Table 2 here]}

First, since we assume Home imports the pure consumption good, $(1+\tau) a_{1} / a_{2}<a_{1} * / a_{2} *$ is necessary to be true, hence requiring $a_{1} *=(1+\tau) a_{1} a_{2} * / a_{2}+0.02$. Thus, the strength of Home's comparative advantage in the investment good increases with $a_{1} *$. As shown in row 6 of Table 2, we find that the better-off region in the home country disappears when the strength is too large $\left(a_{1} * \geq 0.04\right)$. However, the better-off region re-appears when the knowledge spillover effect is sufficient large as in row 7 of Table 2.

Second, the better-off region in the home country also disappears when the knowledge spillover effect is too small $(\alpha \leq 0.04)$ as shown in row 9 of Table 2 . The region re-appears with a sufficient low $a_{1} *$ as depicted in row 10 of Table 2. 


\section{Concluding Remarks}

We have presented a basic two-country endogenous growth model, which is regarded as an integration of a two-country economy and endogenous growth. Four results are derived. First, unlike the past literature, we do not need to make an assumption such that the growth rates between countries are identical in BGP. Second, we show that there exists a unique and saddle-point long-run equilibrium with both countries being incompletely specialized. Third, a higher import tariff may boost (reduce) the economic growth rate when the foreign (domestic) country has absolute advantage in the investment good. Finally, a rise in the tariff rate by one country may improve world welfare under some parameter spaces.

Since the model is a basic one, there are many directions to extend this model to discuss trade and growth issues. One direction extends this model to include two factors, such as physical capital and labor or physical capital and human capital. This may re-examine the hypothesis of the Heckscher-Ohlin model. Moreover, international knowledge is a public good in this model, but in the real world most of these are a private good. If the firms absorbing international knowledge should pay the cost, then we can extend this model to a R\&D structure such as in Romer (1990). 


\section{Appendix A}

This appendix analyzes the slope of the left-hand side (LHS) of (20). We differentiate LHS by $\tilde{v}$ under $\rho=\rho^{*}$ to get:

$$
\begin{aligned}
\frac{d L H S}{d \tilde{v}}= & \frac{y_{2}}{k_{2}} \frac{\left\{(\alpha+\eta) \tilde{v}[1-\tilde{v}+\alpha(\tilde{v}-\alpha)]-\alpha^{2}(\tilde{v}-\alpha)\left(\tilde{v}-\tilde{v}^{*}\right)\right\}}{\tilde{v}(1-\tilde{v})(\alpha+\eta)} \\
& +\frac{y_{2}^{*}}{k_{2}^{*}} \frac{\alpha \tilde{n}\left\{(\alpha+\eta) \tilde{v}^{*}\left[1-\tilde{v}^{*}+\eta\left(\tilde{v}^{*}-\eta\right)\right]-\eta(1-\eta)\left(\tilde{v}^{*}-\eta\right)\left(\tilde{v}-\tilde{v}^{*}\right)\right\}}{\tilde{v}(1-\tilde{v})(\alpha+\eta) \eta} \\
& +\frac{\alpha\left(\tilde{v}-\tilde{v}^{*}\right)}{\tilde{v}(1-\tilde{v})(\alpha+\eta)} \rho \tilde{n}>0 \text { if } \tilde{v}>\tilde{v}^{*}, \\
= & \frac{y_{2}}{k_{2}} \frac{\left\{(\alpha+\eta) \tilde{v}[1-\tilde{v}+\alpha(\tilde{v}-\alpha)]-\alpha(1-\alpha)(\tilde{v}-\alpha)\left(\tilde{v}^{*}-\tilde{v}\right)\right\}}{\tilde{v}(1-\tilde{v})(\alpha+\eta)} \\
& +\frac{y_{2}^{*}}{k_{2}^{*}} \frac{\alpha \tilde{n}\left\{(\alpha+\eta) \tilde{v}^{*}\left[1-\tilde{v}^{*}+\eta\left(\tilde{v}^{*}-\eta\right)\right]-\eta^{2}\left(\tilde{v}^{*}-\eta\right)\left(\tilde{v}^{*}-\tilde{v}\right)\right\}}{\tilde{v}(1-\tilde{v})(\alpha+\eta) \eta} \\
& +\frac{\alpha\left(\tilde{v}^{*}-\tilde{v}\right)}{\tilde{v}(1-\tilde{v})(\alpha+\eta)} \rho>0 \text { if } \tilde{v}<\tilde{v}^{*} .
\end{aligned}
$$

We find it is increasing in $\tilde{v}$.

\section{Appendix B}

This appendix derives the result of the relationship between a tariff and growth. We totally differentiate the three equations, (13), (19a), and (19b), to yield (23a), (23b), and (23c). The result after this differentiation is:

$$
\left(\begin{array}{ccc}
\frac{\alpha}{\tilde{v}(1-\tilde{v})} & \frac{-\eta}{\tilde{v}^{*}\left(1-\tilde{v}^{*}\right)} & 0 \\
\frac{\alpha}{1-\tilde{v}} & \frac{-\eta}{1-\tilde{v}^{*}} & \frac{\alpha+\eta}{\tilde{n}} \\
\frac{\alpha}{1-\tilde{v}}+\frac{1-\eta}{\Lambda} & \frac{(1-\alpha) \tilde{n}}{\Lambda} & \frac{\alpha}{\tilde{n}}+\frac{(1-\alpha)\left(\tilde{v}^{*}-\eta\right)}{\Lambda}-\frac{1}{1+\tilde{n}}
\end{array}\right)\left(\begin{array}{c}
d \tilde{v} \\
d \tilde{v}^{*} \\
d \tilde{n}
\end{array}\right)=\left(\begin{array}{c}
\frac{1}{1+\tau} d \tau \\
0 \\
0
\end{array}\right),
$$

where $\Lambda$ is defined in (23c). Hence, (23a)-(23c) are derived by Cramer's rule. Finally, based on (24) and utilizing (23a) and (23c), the tariff effect on the growth rate is: 


$$
\begin{aligned}
\frac{d g}{d \tau} & =(g+\rho) \alpha\left(\frac{1}{\tilde{n}} \frac{d \tilde{n}}{d \tau}+\frac{1}{1-\tilde{v}} \frac{d \tilde{v}}{d \tau}\right) \\
& =\frac{(g+\rho) \alpha \eta}{\Delta(1+\tau) \tilde{n}(1+\tilde{n})(1-\tilde{v})\left(1-\tilde{v}^{*}\right) \Lambda}\left\{-\tilde{n}(1-\eta)(\tilde{v}-\alpha)+\tilde{n}(1-\alpha)\left(\tilde{v}^{*}-\eta\right)\right. \\
& =\frac{(g+\rho) \alpha \eta(1-\alpha)}{\Delta(1+\tau) \tilde{n}(1+\tilde{n})(1-\tilde{v})\left(1-\tilde{v}^{*}\right) \Lambda}\left\{\tilde{v}+\tilde{n}^{2}\left(1-\tilde{v}^{*}\right)-1\right\} \text { if } \alpha=\eta \\
& =\frac{(g+\rho) \alpha \eta(1-\alpha)}{\Delta(1+\tau) \tilde{n}(1+\tilde{n})\left(1-\tilde{v}^{*}\right) \Lambda}\left\{\left(\frac{a_{2}^{*}}{a_{2}}\right)^{\frac{1}{\alpha}}-1\right\} \geq 0 \text { if } a_{2}^{*}<a_{2},
\end{aligned}
$$

where $\Delta$ is defined in (23c).

\section{Appendix C}

This appendix shows that Home imports the pure consumption good and exports the pure investment good when Home has a comparative advantage in the pure investment good i.e. $(1+\tau) a_{1} / a_{2}<a_{1} * / a_{2} *$. Each country's excess demand for the pure consumption good in a BGP is respectively:

$$
\begin{aligned}
& E D=\tilde{c}-\tilde{y}_{1}=\frac{\tilde{k}}{\tilde{p}}\left[\tilde{m}-a_{2} b^{\alpha}\left(\frac{\tilde{n}}{1-\tilde{v}}\right)^{\alpha} \tilde{v}\right], \\
& E D^{*}=\tilde{c}^{*}-\tilde{y}_{1}^{*}=\frac{\tilde{k}}{\tilde{p}} \tilde{n}\left[\tilde{m}^{*}-a_{2}^{*} b^{* \eta}\left[\frac{1}{\left(1-\tilde{v}^{*}\right) \tilde{n}}\right]^{\eta} \tilde{v}^{*}\right] .
\end{aligned}
$$

We know that in an autarkic economy, $E D=0=E D^{*}$, and in a free-trade economy, $E D+E D^{*}=0$.

Under $\alpha=\eta$ and $\rho=\rho^{*}$, the system of BGP becomes:

$$
\begin{aligned}
& \frac{\tilde{v}}{1-\tilde{v}}=\left(\frac{(1+\tau) a_{1} a_{2}^{*}}{a_{1}^{*} a_{2}}\right)^{\frac{1}{\alpha}} \frac{\tilde{v}^{*}}{1-\tilde{v}^{*}}, \\
& a_{2}\left(\frac{\tilde{n}}{1-\tilde{v}}\right)^{\alpha}=a_{2}^{*}\left[\frac{1}{\left(1-\tilde{v}^{*}\right) \tilde{n}}\right]^{\alpha}, \\
& \rho(1+\tilde{n})=a_{2}\left(\frac{\tilde{n}}{1-\tilde{v}}\right)^{\alpha}(\tilde{v}-\alpha)+a_{2}^{*}\left[\frac{1}{\left(1-\tilde{v}^{*}\right) \tilde{n}}\right]^{\alpha} \tilde{n}\left(\tilde{v}^{*}-\alpha\right) .
\end{aligned}
$$

With the help of (18a)-(18b) and (C4), the excess demand for the pure consumption good is: 


$$
\begin{aligned}
& E D=\frac{\tilde{k}}{\tilde{p}}\left[\rho-a_{2}\left(\frac{\tilde{n}}{1-\tilde{v}}\right)^{\alpha}(\tilde{v}-\alpha)\right], \\
& E D^{*}=\frac{\tilde{k}}{\tilde{p}} \tilde{n}\left[\rho-a_{2}\left(\frac{\tilde{n}}{1-\tilde{v}}\right)^{\alpha}\left(\tilde{v}^{*}-\alpha\right)\right] .
\end{aligned}
$$

With $(1+\tau) a_{1} / a_{2}<a_{1} * / a_{2}^{*},(\mathrm{C} 3)$ implies that $\tilde{v}^{*}>\tilde{v}$, and then the value of the square bracket in (C6) is greater than that in $(\mathrm{C} 7)$. Thus, $E D>0>E D^{*}$, which means that Home imports the pure consumption good and exports the pure investment good. 


\section{References}

Arrow, K.J., 1962. The economic implications of learning by doing. Review of Economic Studies $29,155-173$.

Ben-David, D. and M.B. Loewy, 1998. Free trade, growth, and convergence, Journal of Economic Growth 3, 143-170.

Benhabib, J., Meng Q., Nishimura, K., 2000. Indeterminacy under constant returns to scale in multisector economics. Econometrica 68, 1541-1548.

Bond, E.W., K. Trask and P. Wang. 2003. Factor accumulation and trade: dynamic comparative advantage with endogenous physical and human capital, International Economic Review 44, 1041-1060.

Chen, B.-L., S.-F. Lee and K. Shimomura, 2009. Import tariffs and growth in a model with habits, International Trade and Economic Dynamics, edited by Takashi Kamihigashi and Laixun Zhao, Berlin Heidelberg: Springer-Verlag Press, 299-322.

Clements, M.A. and J.G. Williamson, 2004. Why did the tariff-growth correlation change after 1950? Journal of Economic Growth 9, 5-46.

Coe, D.T., and E. Helpman. 1995. International R\&D spillovers, European Economic Review 39, 859-887.

Doi, J., K. Nishimura and K. Shimomura. 2007. A two-country dynamic model of international trade and endogenous growth: Multiple balanced growth paths and stability, Journal of Mathematical Economics 43, 390-419.

Drugeon, J.-P., Venditti, A., 2001. Intersectoral external effects, multiplicities and indeterminacies. Journal of Economic Dynamics and Control 25, 765- 787.

Drugeon, J.-P., Poulsen, O., Venditti, A., 2003. On intersectoral allocations, factors substitutability and multiple long-run growth paths. Economic Theory 21, 175- 183.

Easterly, W. and S. Rebelo, 1993. Fiscal policy and economic growth, Journal of Monetary Economics 32, 417-458.

Eaton, J., and S. Kortum 1999. International Patenting and Technology Diffusion: Theory and Measurement, International Economic Review 40, 537-570.

Edwards, S., 1992. Trade orientation, distortions and growth in developing countries, Journal of Development Economics 39, 31-57.

Farmer, Roger E.A. and A. Lahiri. 2005. A two-country model of endogenous growth, Review of Economic Dynamics 8, 68-88. 
Fukushima, T. and N. Kim, 1989. Welfare improving tariff changes: a case of many goods and countries, Journal of International Economics. 26, pp. 383-388.

Grossman, G.M. and E. Helpman, 1990. Comparative advantage and long-run growth, American Economic Review 80, 796-815.

Harrison, A., 1996. Openness and growth: a time series, cross-country analysis for developing countries, Journal of Development Economics 48, 419-447.

Hatta, T. and T. Fukushima, 1979. The welfare effect of tariff rate reductions in a many-country world, Journal of International Economics 9, pp. 503-511.

Irwin, D.A., 2002. Interpreting the tariff-growth correlation of the late nineteenth century, NBER Working Paper Series, No. 8739.

Jones, L.E. and R. Manuelli, 1990. A convex model of equilibrium growth, Journal of Political Economy 98, 1008-1037.

Keller, W. 2002. Geographic localization of international technology diffusion, American Economic Review 92, 120-142.

Lee, J.-W., 1993. International trade, distortions, and long-run economic growth, IMF Staff Papers 40, 299-328.

Lucas, Jr., R., 1988. On the mechanics of economic development, Journal of Monetary Economics $22,3-42$.

Mino, K., 2001. Indeterminacy and endogenous growth with social constant returns. Journal of Economic Theory 97, 203-222.

Naito, T., 2006a. Tariff and tax reform: dynamic implications. Journal of International Economics 68, 504-517.

Naito, T., 2006b. Growth, revenue, and welfare effects of tariff and tax reform: win-win-win strategies, Journal of Public Economics 90, 1263-1280.

Nakanishi, N. 1993. Welfare analysis of tariff and without international change with transfers, Journal of International Economics 35, 377-387.

Nishimura, K., Venditti, A., 2002. Intersectoral externalities and indeterminacy. Journal of Economic Theory 105, 140-157.

O'Rourke, K.H., 2000. Tariffs and growth in the late nineteenth century, Economic Journal 110, 456-483.

Osang, T. and A. Pereira, 1996. Import tariffs and growth in a small open economy, Journal of Public Economics 60, 45-71. 
Park, W. 1995. International R\&D spillovers and OECD economic growth, Economic Inquiry 23, 571-591.

Rebelo, S., 1991. Long-run policy analysis and long-run growth, Journal of Political Economy, 99, 500-521.

Rivera-Batiz, L.A. and P.M. Romer, 1991. International trade with endogenous technological change, European Economic Review 35, 971-1004.

Romer, Paul M. 1986. Increasing returns and long-run growth, Journal of Political Economy 94, 1002-1037.

Romer, Paul M. 1990, Endogenous technological change, Journal of Political Economy 98, s71-s102.

Ventura, J. 1997. Growth and interdependence, Quarterly Journal of Economics 112, 57-84.

Yanikkaya, H., 2003. Trade openness and economic growth: a cross-country empirical investigation, Journal of Development Economics 72, 57-89. 
Table 1: Benchmark parameter values

\begin{tabular}{ccccccccccc}
\hline \hline$k_{0}$ & $k_{0}^{*}$ & $\rho$ & $\rho^{*}$ & $\alpha$ & $\eta$ & $\tau$ & $a_{1}$ & $a_{2}$ & $a_{2}^{*}$ & $a_{1}^{*}$ \\
\hline 1 & 1 & 0.025 & 0.025 & 0.05 & 0.05 & 0.0167 & 1 & {$[0,4]$} & {$[0,4]$} & {$\left[(1+\tau) a_{1} a_{2} * / a_{2}\right]+0.02$.} \\
\hline \hline
\end{tabular}

Table 2: Robustness Analysis

\begin{tabular}{|c|c|c|c|c|}
\hline Variations & Country & $\begin{array}{l}\text { Lowest point in } \\
\qquad\left(a_{2}, a_{2}{ }^{*}\right)\end{array}$ & $\begin{array}{l}\text { Highest point in } \\
\qquad\left(a_{2}, a_{2}{ }^{*}\right)\end{array}$ & Better-off Region \\
\hline \multirow{2}{*}{ Benchmark $^{1}$} & Home & $(0.62,0.73)$ & $(1.39,1.39)$ & Figure 2 \\
\hline & Foreign & $(0.02,0.03)$ & $(2.06,1.97)$ & Figure 3 \\
\hline \multirow{2}{*}{$\rho=0.05$} & Home & $(2.00,2.44)$ & $(2.41,2.49)$ & Similar \\
\hline & Foreign & $(0.04,0.05)$ & $(4.00,3.72)$ & Similar \\
\hline \multirow{2}{*}{$\rho=0.01$} & Home & $(0.02,0.01)$ & $(0.66,0.67)$ & Similar \\
\hline & Foreign & $(0.01,0.01)$ & $(0.84,0.84)$ & Similar \\
\hline \multirow{2}{*}{$\begin{aligned} a_{1} *= & {\left[(1+\tau) a_{1} a_{2} * / a_{2}\right]+} \\
& 0.01\end{aligned}$} & Home & $(0.72,0.85)$ & $(1.98,1.99)$ & Similar \\
\hline & Foreign & $(0.02,0.03)$ & $(3.78,2.93)$ & Similar \\
\hline \multirow{2}{*}{$\begin{array}{c}a_{1}^{*}=\left[(1+\tau) a_{1} a_{2} * / a_{2}\right]+ \\
0.03\end{array}$} & Home & $(0.56,0.64)$ & $(0.59,0.66)$ & Similar \\
\hline & Foreign & $(0.02,0.03)$ & $(1.32,1.29)$ & Similar \\
\hline \multirow{2}{*}{$\begin{array}{c}a_{1}^{*}=\left[(1+\tau) a_{1} a_{2} * / a_{2}\right]+ \\
0.04\end{array}$} & Home & - & - & Disappear \\
\hline & Foreign & $(0.02,0.03)$ & $(0.92,0.90)$ & Similar \\
\hline \multirow{2}{*}{$\begin{array}{c}a_{1} *=\left[(1+\tau) a_{1} a_{2} * / a_{2}\right]+ \\
0.04 \\
\alpha=\eta=0.1\end{array}$} & Home & $(0.22,0.36)$ & $(0.91,0.92)$ & Similar \\
\hline & Foreign & $(0.02,0.02)$ & $(1.71,1.36)$ & Similar \\
\hline \multirow{2}{*}{$\alpha=\eta=0.1$} & Home & $(0.22,0.43)$ & $(1.45,1.46)$ & Similar \\
\hline & Foreign & $(0.02,0.02)$ & $(3.94,2.22)$ & Similar \\
\hline \multirow{2}{*}{$\alpha=\eta=0.04$} & Home & - & - & Disappear \\
\hline & Foreign & $(0.03,0.02)$ & $(1.82,1.78)$ & Similar \\
\hline \multirow{2}{*}{$\begin{array}{c}\alpha=\eta=0.04 \\
a_{1} *=\left[(1+\tau) a_{1} a_{2} * / a_{2}\right]+ \\
0.01\end{array}$} & Home & $(1.61,1.83)$ & $(1.98,1.99)$ & Similar \\
\hline & Foreign & $(0.02,0.03)$ & $(3.41,3.03)$ & Similar \\
\hline
\end{tabular}

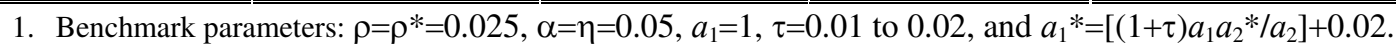


Figure 1: Existence of BGP

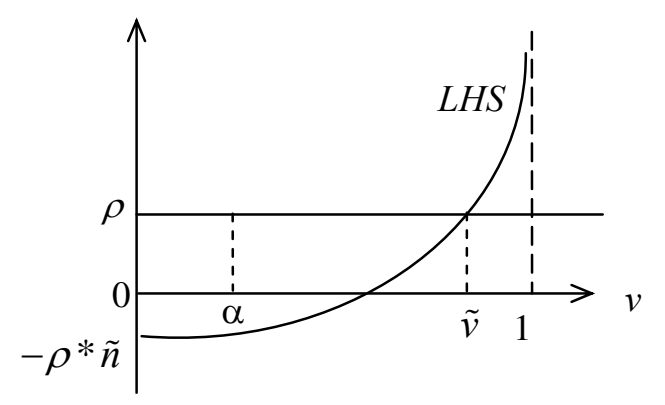


Figure 2: Home's welfare analysis

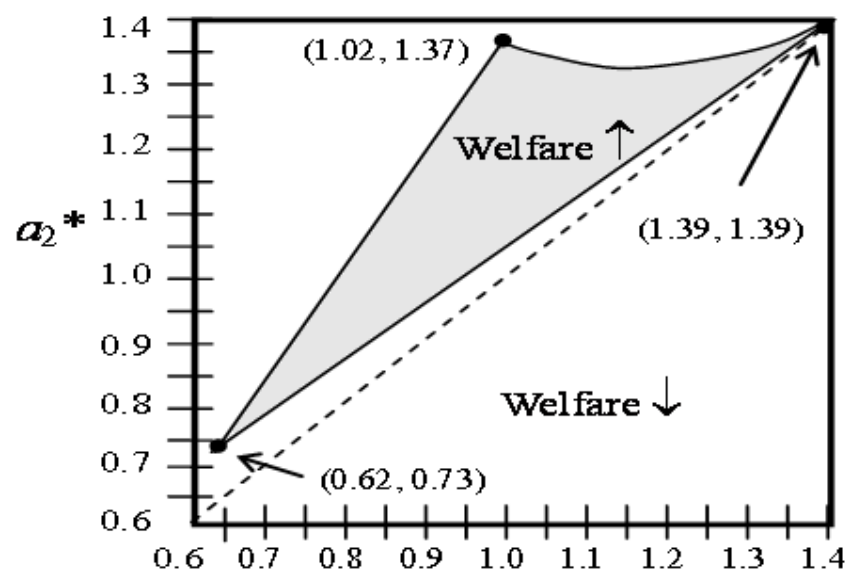

\section{Note:}

$a_{2}$

1. $\rho=\rho^{*}=0.025, \alpha=\eta=0.05, a_{1}=1, \tau=0.01$ to 0.02 and $a_{1}^{*}=\left[(1+\tau) a_{1} a_{2} * / a_{2}\right]+0.02$.

2. The shaded area presents the region for better-off welfare.

Figure 3: Foreign's welfare analysis

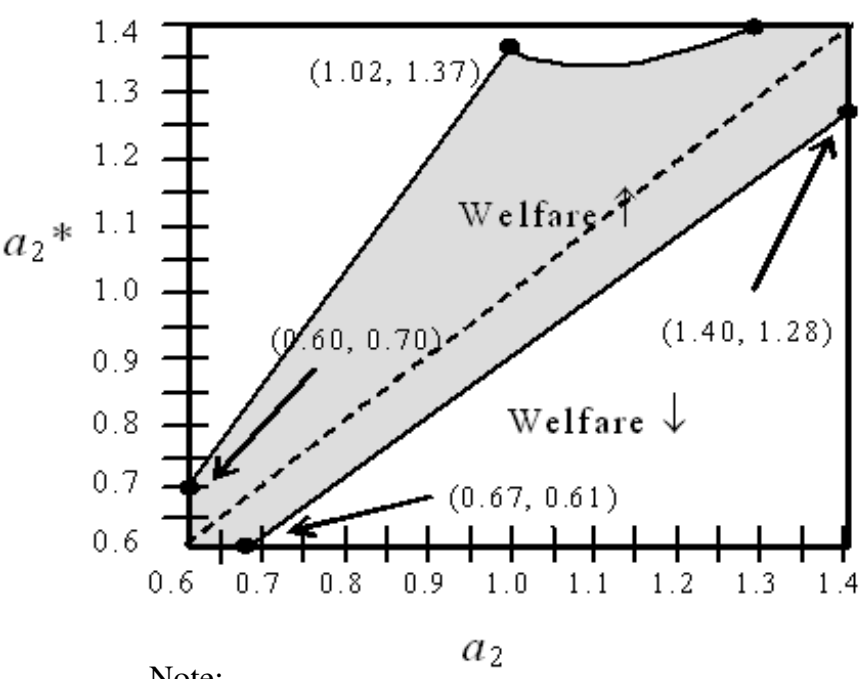

1. $\rho=\rho^{*}=0.025, \alpha=\eta=0.05, a_{1}=1, \tau=0.01$ to 0.02 and $a_{1}^{*}=\left[(1+\tau) a_{1} a_{2} * / a_{2}\right]+0.02$.

2 . The shaded area presents the region for better-off welfare in the foreign country. 